\title{
International Organizations as Policy Advisors
}

\author{
Songying Fang and Randall W. Stone
}

\begin{abstract}
How can international organizations persuade governments to adopt policy recommendations that are based on private information when their interests conflict? We develop a game-theoretic model of persuasion that applies regardless of regime type and does not rely on the existence of domestic constituency constraints. In the model, an international organization (IO) and a domestic expert have private information about a crisis, but their preferences diverge from those of the government, which must choose whether to delegate decision making to the expert. Persuasion can take place if the international institution is able to send a credible signal. We find that this can take place only if the preferences of the IO and the domestic expert diverge and the institution holds the more moderate policy position. This result contrasts with conventional wisdom, which holds that the necessary condition for IOs to exert influence is support from a domestic constituency with aligned preferences. Our model suggests that, far from being an obstacle to international cooperation, polarized domestic politics may be a necessary condition for IOs to exert effective influence.
\end{abstract}

International organizations (IOs) have been tasked with providing early warnings on a wide range of issues, but state leaders and informed publics have become increasingly skeptical about their policy advice. There are inherent conflicts of interest between IOs and their individual member states, and the legitimacy of important IOs is subject to persistent challenges. The effectiveness of international institutions as policy advisors depends on trust. Under what conditions can an international institution credibly convey information to a government that does not share its preferences?

Consider three examples. In 2007, the Intergovernmental Panel on Climate Change (IPCC) issued its Fourth Assessment Report, which summarized recent research indicating that global climate change was progressing more rapidly than previously believed and called for dramatic reductions in carbon emissions. It has no power to enforce these recommendations. In 2003, the World Health Organiza-

We thank Philip Arena, Camelia Bejan, Xinyuan Dai, Mark Fey, Thomas Dolan, Justin Fox, Erik Gartzke, Jin Li, Jeff Marshall, Kristopher Ramsay, Branislav Slantchev, Johannes Urpelainen, Erik Voeten, Jingyi Xue, and seminar participants at the Watson Center for Conflict and Cooperation at the University of Rochester, and the Department of Political Science, University of Pittsburgh.

International Organization 66, Fall 2012, pp. 537-69

(C) 2012 by The IO Foundation.

doi:10.1017/S0020818312000276 
tion (WHO) warned that a viral outbreak in southern China posed a global health risk, coined the term Severe Acute Respiratory Syndrome (SARS), and called on the Chinese government to take remedial action. The WHO has no enforcement powers. In the months and years leading up to the currency crises in Brazil in 1999 and Argentina in 2001, the International Monetary Fund (IMF) sought to warn the respective governments that their exchange rate policies were unsustainable in the absence of painful budget cuts. During most of this time, the IMF had no active lending facility with either country, so it had to rely on persuasion. In each case, governments were skeptical because IOs do not bear the costs of policy changes. Successful warnings are possible only when the IO is credible, and we argue that this depends on domestic conditions.

We seek to address three limitations in the existing rational-choice literature on international institutions. First, the literature has generally neglected the possibility that IOs might give their members deceptive advice. ${ }^{1}$ Formal models of IO influence typically assume that differences arise between the policy preferences of IOs and national leaders because leaders are biased, and IOs can solve the problem by speaking directly to voters who share their preferences and are in a position to punish the leaders for undesirable policies. ${ }^{2}$ However, the conflict of interest between states and IOs may be more fundamental, arising from the fact that IOs are multilateral bodies with different policy goals than individual governments. IOs that pursue their own agendas may have incentives to misrepresent their private information. Second, while this literature has identified important domestic mechanisms of IO influence, the focus on electoral mechanisms has limited its scope to democracies. The literature has had little to say, for example, about how an IO can influence the policies of an authoritarian government. ${ }^{3}$ Third, the formal literature on communication concludes that agents can only credibly transmit messages that run counter to their biases. However, IOs often need to communicate information that appears to corroborate their known biases. For example, how can the WHO send a credible warning about a global health crisis if it is perceived as holding a bias in favor of taking extreme precautions? The literature in economics and political science on information transmission suggests that it cannot; communication fails when the true state of the world corresponds to claims that the biased agent has an incentive to make. A general theory of IO crisis management

1. There are two related formal literatures on opportunism by IOs, but neither addresses this problem. Principal-agent models of delegation consider IO opportunism when given discretion. Hawkins et al. 2006. Procedural models of legislation in the European Union consider the opportunities for supranational bodies to exert influence by setting the agenda. Thomson et al. 2006. Neither considers the possibility that an IO strategically manipulates private information in order to influence the policies of a member state. An exception is Johns 2007, which considers the choice of an international agent by two states that bargain over a policy, and argues that choosing a biased agent may be optimal for member states. The problem we analyze here is the reverse: given that an IO has different preferences than a government, under what conditions can the IO give credible advice?

2. See Dai 2007; Fang 2008; Milner 1997; and Chapman 2009.

3. Simmons 2009 is a prominent exception that offers a domestic mechanism of IO influence that applies to nondemocracies, but focuses on treaties as coordination devices rather than on IOs as sources of information. 
should address all three of these concerns. It should provide a causal mechanism that applies in both democratic and nondemocratic contexts, which sheds light on how IOs can build trust with governments despite their conflicts of interest, and which explains how IOs can communicate information effectively even when the information appears to confirm their known biases.

We develop a game theoretic model of persuasion that applies to all types of governments. In democratic and nondemocratic political systems alike, leaders must decide how to allocate their attention across a variety of issues, and as a result they must be rationally ignorant, or at least relatively uninformed, about some public policy issues. When an international institution perceives a potential crisis situation, it can raise the profile of one of these issues by sending a signal that the state of the world urgently demands policy change. In response, the government can either implement a policy directly or delegate the decision to a domestic agent who has special expertise. We assume that the leader generally finds it costly to adjust policy. The costs could take the form of budgetary expenses, loss of reputation involved in admitting mistakes, or imposing costs on important constituents; more generally, they reflect the assumption that prior policies were chosen because they were politically optimal, so deviating from them is costly. The IO and domestic experts do not internalize such costs, so from the government's point of view, their advice is unreliable. When the government delegates, therefore, it allows an agent with different preferences to influence its policies in ways that it might not choose were it more fully informed. However, it may nevertheless prefer to delegate the policy to domestic experts if policy change is not too costly and domestic experts have valuable expertise. Under some circumstances, the IO has an incentive to misrepresent its information to induce the government to delegate the decision making to the expert. The model thus identifies a conflict of interest between a government and an IO but finds conditions under which the IO can nevertheless effectively transmit information and influence a government's policy.

We contrast the results of three versions of the model. In the baseline model there are only unbiased experts who share the objectives of the IO and want to adopt the most appropriate policy given the state of the world. Extensions of the model allow for two ways in which the domestic expert may be biased, either having a preference to take precautions against potential crises even when the objective situation indicates that they are unwarranted, or to maintain the status quo policy regardless of the state of the world.

In the baseline model, with unbiased experts, we find that there is no truthtelling equilibrium in which the IO honestly reports its private information to the government and the government acts on it. ${ }^{4}$ When the cost of implementing the pol-

4. A truth-telling equilibrium requires that it is incentive compatible for the agent to send a truthful report if the report will be believed and affect the recipient's strategy. When such an equilibrium does not exist, the agent (in this case, the IO) has an incentive to misrepresent its private information. In our model, the IO does not know the true state of the world with certainty, but it may misrepresent its beliefs. In particular, when it receives a low signal, the IO may have an incentive to recommend a policy that the government would prefer to take only if the IO had in fact received a high signal. 
icy is too high or too low, the government's policy choice will not be affected by the institution's signal; when the cost is in the middle range where the institution's information matters, however, the institution has an incentive to misrepresent the signal that it receives to motivate the government to delegate the policy to the expert. As a result, a truth-telling equilibrium does not exist. Ironically, however, the existence of biased experts who always prefer the precautionary policy makes credible communication possible. When experts are unbiased, the IO categorically prefers that the government delegate to the expert, so the IO's advice is not credible. When experts are expected to be biased in favor of an extreme policy with a high probability, however, there exist conditions under which the IO might prefer that the experts control the policy only if it honestly believes that the state of the world is favorable for an activist response. In this case, the IO sends different messages when it receives different signals, so the government can rationally believe the IO's recommendation, and this can lead it to delegate authority to an expert. Finally, in the case where the expert is biased with a high probability but in the opposite direction, in favor of maintaining the status quo, we again obtain the result that there is no truth-telling equilibrium.

We build on a literature that investigates the mechanisms for IOs to exert influence over democracies, but identify a common mechanism-empowerment of domestic experts - that can operate in both democratic and nondemocratic contexts. The IO in our model does not directly recommend policies or suggest personnel changes to the government, but it exercises influence when it is able to send a credible signal to the government. Our model relates to the literature on principal-agent relationships, which has developed to explain why principals delegate and whether, given divergent preferences, truthful information can be transmitted between the agent and the principal. ${ }^{5}$ We find that the existence of two agents with divergent interests—-the IO and the domestic policy expert—makes credible information transmission possible in such circumstances. Our ironic result is that the necessary condition for trust between the IO and the government is their shared mistrust of the domestic expert. This contrasts with the conventional wisdom, which holds that the domestic conditions that are most favorable for IO influence arise when domestic constituencies have preferences that are closely aligned with those of the IO.

\section{Trust and Information Transmission}

International institutions influence state policies and promote multilateral cooperation in a number of ways, but most accounts of their influence deemphasize overt coercion and emphasize instead the role of information. ${ }^{6}$ Most institutions are incapable of coercing their members and instead foster cooperation by providing infor- 
mation and expertise, or by authoritatively defining rules and expectations. ${ }^{7}$ Even institutions that have some coercive powers on paper generally find them difficult to deploy, and exercise more influence as referees than as a police force. Persuasion is key to the influence of IOs.

Trust, in turn, is a necessary condition for successful persuasion. If governments perceive that international institutions are pursuing policies detrimental to their interests, they disregard their policy advice. Cheap talk is cheap; in general, it is difficult to credibly share information when there is a conflict of interest. ${ }^{8}$ Recent contributions to international relations have treated trust as a fundamental factor in international security. Sartori argues that the reputation for truth-telling plays an important role in avoiding international conflict, and Kydd explores the effects of trust and mistrust on conflict and cooperation during the Cold War. ${ }^{9}$ Trust is similarly important in the relations between states and IOs. Trust is problematic because IOs have incentives to misrepresent their private information to encourage governments to choose policies that they prefer. Prominent accounts of the IMF, for example, focus on the tension between national objectives and international agendas. ${ }^{10}$ Potential conflict of interest between IOs and national governments is an essential feature of a model of persuasion, and the question is whether information can be transmitted credibly in this environment.

While the existing formal literature recognizes that conflicts of interest arise between governments and IOs, it sidesteps the problem of credible communication that is our focus. The standard setup for such models treats IOs as nonstrategic actors that make technocratic recommendations, and focuses on uncertainty about the type of the national leader, who has incentives to adopt short-term or self-interested policies. The incentives and strategies of IOs are unproblematic by assumption. ${ }^{11}$ This modeling convention may be appropriate for some purposes; however, the mistrust that it assumes away is substantively important, and may play a key role in determining IO effectiveness. It is likely that preferences diverge simply because IOs are multilateral bodies; in the best case scenario, the preferences of international institutions reflect some aggregation of the preferences of their member states. In a crisis situation where global public health or financial stability are in the balance, an international body is unlikely to have the same perspective as the government that is in charge on the ground or the public in the affected country. Local actors do not necessarily internalize the global consequences of the crisis, and local actors, rather than the IO, bear the costs of the policy responses. Under these circumstances, the IO may not be able to credibly convey the private information that it has. Trust may not be possible.

The economic literature on information transmission between a principal and an agent finds that the information content of messages declines as interests become

7. Barnett and Finnemore 2004.

8. Fearon 1995.

9. See Sartori 2005; and Kydd 2005.

10. See Vreeland 2003; Dreher and Vaubel 2004; and Woods 2006.

11. See Dai 2005; Fang 2008; and Chapman 2009. 
more conflictual. ${ }^{12}$ A related literature on third-party mediation in political science finds that biased mediators are more effective than unbiased ones, because biased mediators can credibly convey information that is contrary to their own biases. ${ }^{13}$ Similarly, a literature in economics explores the conditions under which governments can credibly convince voters that the state of the world justifies policy change, and concludes that such arguments are credible only when they run counter to the government's known policy preferences. ${ }^{14}$ All of this literature suggests that persuasion should be difficult for IOs because conflicts of interest frequently arise between IOs and the governments that they attempt to coordinate. Moreover, the problem may be intractable in crisis situations because in those cases IOs have to convince skeptical governments to heed their alarms, in spite of the fact that they have incentives to send warnings even in good times. In other words, in order for IOs to be effective information providers, they need to gain trust even when their information seems to confirm their biases. Under what circumstances can persuasion succeed in spite of the fact that governments know that international institutions have different objectives than they do?

Combining domestic experts and IOs provides a mechanism to explain the spread of ideas and change in state behavior. ${ }^{15}$ IOs influence government policy by engaging in persuasion, which in terms of our model means that rational government agents choose to respond to the IO's signals by adjusting their policies. Persuasion is possible only if the government trusts the IO as a source of information, and in the context of the model, trust is possible only if truth-telling is an optimal strategy for the IO. Therefore, we solve for truth-telling equilibria in which the IO truthfully reveals its signal about the state of the world, and in turn, the government believes the message sent by the IO. We find that domestic experts play a key role in allowing effective information transmission to take place at the international level. The analysis thus identifies conditions under which trust can be built between an IO and a government, conditions that allow the IO to influence the government's policy through its message. Moreover, expert influence is a mechanism that applies to autocratic as well as to democratic states, so it offers a general explanation for IO influence.

The substantive claim underlying our model is that IOs exercise much of their influence by empowering local experts. This may occur at the level of interactions between national leaders and cabinet ministers, or at lower levels of the bureaucracy. The agents in our model can be interpreted as a head of government who

12. Crawford and Sobel 1982.

13. See Calvert 1985; and Kydd 2003.

14. See Cukierman and Tommasi 1998; and Drazen and Masson 1994.

15. Domestic experts can be thought of as policy entrepreneurs, which figure prominently in work in international relations and comparative politics on the influence of ideas. Goldstein and Keohane 1993. For example, Checkel 1997 describes the origin of the New Thinking under Soviet leader Mikhail Gorbachev in terms of policy entrepreneurs. 
appoints a minister, a minister who appoints a deputy, a deputy who appoints a department head, etc. At each link in the delegation chain, the ubiquitous conflicts of interest between IOs and their member states render the policy advice that IOs provide in times of crises immediately suspect; however, the existence of domestic experts mitigates the problem of mistrust. This mechanism does not depend on the local experts being more trustworthy than the international ones-in fact, as we show, the mechanism breaks down if they are too trustworthy. Instead, the mechanism works because the IO is reluctant to empower biased local experts, so when it does send a crisis message in spite of the fact that local experts may be biased, the message is credible. The mechanism of the model does depend on the assumption that local experts have an information advantage over their government superiors and over the IO. Delegation is generally optimal only if the agent has an information advantage. In this case, the information advantage relates to local conditions. IOs may have superior scientific expertise, but there is generally some advantage to local knowledge, so it would be impractical for the IO to devise an optimal policy independently.

Global climate change provides an example of the operation of this mechanism. Joseph Fourier discovered the greenhouse effect in 1824, and Svante Arrhenius linked it to carbon dioxide levels in 1896, but a scientific consensus about anthropogenic climate change emerged only around 1990, with the publication of the first report of the IPCC. Substantial uncertainty remains about the likely extent of global climate change, its local consequences, and the effect of measures to reduce carbon emissions, and many skeptical governments, particularly in developing countries, have chosen not to implement costly policy changes. Several IOs formed around the United Nations Framework Convention on Climate Change (UNFCCC) in 1992, including a secretariat that has organized a series of annual Conferences of the Parties (COP1-COP17), and these have formed a platform to publicize the reports of the IPCC. Developing countries, led by China, refused to adopt quantitative emissions reduction targets in the Kyoto Protocol. Nevertheless, continuous international negotiations have elevated the status of environmental experts in China, and the publication of the Fourth IPCC Assessment Report in 2007 led its Politburo for the first time to devote one of its study sessions to climate change. ${ }^{16}$ In April 2007, Wan Gang, the president of Tongji University, was appointed Minister of Science and Technology-the first cabinet minister in three decades who was not a member of the Communist Party. Wan had a Ph.D. in mechanical engineering from Clausthal University of Technology in Germany and had worked for Audi as an expert in the use of renewable energy in automobiles. China subsequently announced a series of initiatives to reduce the carbon intensity of its economy and has been investing heavily in renewable energy technology. It now appears that China has gradually been persuaded of the significance of climate change, and that the mechanism of persuasion includes a change in personnel. 


\section{Model}

There are three actors in our model: an international institution, $I$, a government, $G$, and a domestic expert, $E$. The state of the world is $\theta \in\{0,1\}$, where 0 represents no crisis, and 1 represents a crisis situation. Each state occurs with equal probability. The institution receives a private signal about the state of the world, $s_{I}$ $\in\{0,1\}$, and then sends a publicly observable message, $m_{I} \in\{0,1\}$, to the government about the signal. If the institution is truthful, the message takes the same value as the signal. The institution's signal is correct with probability $\alpha$ given a state of the world, that is, $\operatorname{Pr}\left(s_{I}=0 \mid \theta=0\right)=\operatorname{Pr}\left(s_{I}=1 \mid \theta=1\right)=\alpha$, where $\alpha$ $\in(1 / 2,1)$. Note that the institution's signal is informative so that it improves on the prior belief of the government, but it is not perfectly correlated with the true state of the world.

After receiving the institution's message, the government can implement a policy $x \in[0,1]$ directly or delegate the decision to the domestic expert. We assume that the status quo policy is consistent with the belief that the state of the world is 0 , and any change of the policy is costly. The expert receives a private signal, $s_{E}$ $\in\{0,1\}$ about $\theta$. We assume that given a state of the world, the expert's signal is independent of the institution's, and is of a higher quality, that is, $\operatorname{Pr}\left(s_{E}=0 \mid \theta\right.$ $=0)=\operatorname{Pr}\left(s_{E}=1 \mid \theta=1\right)=\beta$, where $\beta \in(\alpha, 1]$. The quality of each signal is common knowledge.

There are two types of experts: unbiased and biased. The unbiased type shares the preference of the IO and prefers to implement a policy that corresponds to the state of the world. The biased type prefers a particular policy regardless of the true state of the world. In the baseline model we assume that the expert is unbiased; we then extend the model to cases in which experts may be biased.

To summarize, the sequence of play is as follows. Nature chooses the state of the world, $\theta$. The institution receives a signal, $s_{I}$, and then sends a publicly observable message, $m_{I}$, to the government. After receiving the message, the government can either choose a policy, $x \in[0,1]$, and end the game, or delegate the decision to a domestic expert. If $G$ delegates the decision to the expert, the expert chooses a policy to implement based on $m_{I}$ and its own signal $s_{E}$. (See Figure 1.)

The actors have utility functions as follows. The IO wants to adopt a policy that matches the state of the world. This preference is captured by the following utility function:

$$
u_{I}=\left\{\begin{array}{cc}
-x & \text { if } \theta=0 \\
x-1 & \text { if } \theta=1
\end{array}\right.
$$

From the IO's perspective, when the true state of the world is 0 , policies that deviate from 0 are costly; when the true state of the world is 1 , policies that deviate from 1 are costly. This is consistent with the interpretation that the IO is sensitive to evaluations of its advice that are made after the true state of the world is 


\begin{tabular}{lllll}
$\begin{array}{l}\text { State of the } \\
\text { world selected } \begin{array}{l}I \text { receives } \\
\text { a signal }\end{array}\end{array}$ & $\begin{array}{l}E \text { receives } \\
\text { a signal }\end{array}$ & $\begin{array}{l}I \text { announces } \\
\text { a message }\end{array}$ & $G$ delegates \\
\hline$\theta \in\{0,1\}$ & $s_{I} \in\{0,1\}$ & $s_{E} \in\{0,1\}$ & $m_{I} \in\{0,1\}$ & $\begin{array}{l}\text { chooses } \\
x \in[0,1]\end{array}$ \\
& & $x$ implemented
\end{tabular}

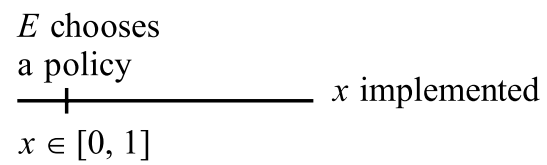

FIGURE 1. Time line of the game

revealed, perhaps because it seeks to maintain a reputation as an honest broker. The government shares the IO's preference to take an action that matches the state of the world; however, it has an additional concern about the cost of changing the status quo, $k>0$. Recall that we assume the status quo policy is consistent with the belief that the state of the world is 0; thus, when the state of the world is believed to be 1, a change in policy is desirable. The government's utility function therefore has two components:

$$
u_{G}=\left\{\begin{array}{cc}
-x-k x & \text { if } \theta=0 \\
x-1-k x & \text { if } \theta=1
\end{array}\right.
$$

The utility function of an unbiased expert is identical to that of the IO. Like the IO, the expert does not internalize the cost of implementing the policy; the expert's only concern is to adopt the most appropriate policy given the state of the world. The cost creates a tension between the government's policy preference and that of the IO and the expert.

The model is a game of incomplete information, and is solved for perfect Bayesian equilibria (PBE) in pure strategies. We assume that when the government is indifferent between choosing a policy directly and delegating the decision to the expert, it chooses a policy directly. ${ }^{17}$

After analyzing the case where the expert is unbiased with certainty, we extend the model to cases where the expert is biased with probability $\pi \in(0,1)$ in favor

17. This is equivalent to assuming that there is a small cost of delegating the policy to the expert. 
of a particular policy, $x=1$ or $x=0$. If the expert is biased toward $x=1$, the expert's utility function is $u_{E}=x-1$. This scenario captures the selection bias in expert recruitment. That is, experts may be policy outliers: they think that the issues related to their expertise are important, and they self-select into their areas of expertise for that reason. For instance, environmental scientists tend to favor environmental causes. If the expert is biased toward policy $x=0$, the expert's utility function is $u_{E}=-x$. This agent has a status-quo bias, which represents an actor who benefits from policy inertia or finds policy change costly. The Chinese party functionaries during the SARS outbreak who preferred to hide the severity of the crisis to minimize social unrest serve as an example. We analyze these three scenarios in turn in the next section.

\section{Equilibrium Results}

The focus of our analysis is whether the IO has an incentive to misrepresent the signal that it receives. If the IO would have an incentive to misrepresent its signal if it were believed, the government must rationally disregard any message the IO sends. Therefore, we solve for truth-telling equilibria. We present three propositions, corresponding to the scenarios with an unbiased expert, with an expert that may be biased in favor of policy activism, and with an expert that may be biased in favor of maintaining the status quo. We first analyze the baseline case where the expert is unbiased.

\section{Unbiased Expert}

We first characterize a truth-telling equilibrium, if it exists. Suppose the government believes that the IO truthfully reveals its signal, and the government decides whether to delegate policy to the expert based on the IO's message. In this case, we find that, all else equal, the government becomes more willing to delegate policy to the expert as the expert's signal $(\beta)$ becomes more accurate, but becomes less willing to delegate as the institution's signal $(\alpha)$ becomes more accurate. The more accurate the expert's signal is, the better the policy choice that the expert makes, which increases the incentive to delegate. However, as the IO's signal becomes more accurate, the marginal policy improvement from delegating policy to the expert declines because the government is able to rely on the IO's message to implement better policies directly. Consequently, the government has an incentive to implement policy directly because the expert does not internalize the cost of policy change as the government does.

The unit cost of implementing a policy, $k$, plays a critical role in the government's decision about whether to delegate. If the cost is high, the government prefers to implement a policy directly to prevent the expert from choosing a costly policy. Specifically, depending on the message sent by the institution, there is a threshold 
cost, $k_{1}=\frac{\beta-\alpha}{\alpha+\beta-\alpha \beta}$ if $m_{I}=0$, and $k_{2}=\frac{\alpha+\beta-1}{1-\alpha-\beta+2 \alpha \beta}$ if $m_{I}=1$, above which the government will not delegate the decision making to an expert.

In contrast, the IO always prefers delegation to an unbiased expert, regardless of the signal it receives. The expected utility for the IO is always higher when the expert rather than the government chooses policy, for two reasons. First, the government has an incentive to choose a lower policy action than is optimal from the IO's perspective, because the government bears the cost of implementing the policy. Second, the expert's signal is more accurate than the IO's, so the expert is positioned to choose a better policy.

Does this conflict of interest create an incentive for the IO to misrepresent its private information to the government? Such an incentive exists in some states of the world if truth-telling would result in the government implementing a policy directly, while sending a warning message would result in the government delegating the decision to the expert. When the cost is no greater than $k_{1}$, or at least as high as $k_{2}$, the institution's message cannot change the government's behavior because the government always delegates when the cost is sufficiently small ( $k$ $\leq k_{1}$ ), and always implements a policy directly when the cost is sufficiently high $\left(k \geq k_{2}\right)$. As a result, the institution's message can be arbitrary for these values of the cost without changing the government's behavior, and thus the IO can be truthful in a trivial sense.

If the cost falls between the two thresholds, that is, $k_{1}<k<k_{2}$, the government will not delegate if it believes that the institution received the signal $s_{I}=0$, but will delegate if it believes that the institution received $s_{I}=1$. Within this range, the institution's signal is sufficiently informative that the expected benefit from letting the expert choose policy outweighs the expected cost of implementing the policy when $s_{I}=1$. However, if the government believes the institution's message and acts accordingly, this scenario provides an incentive for the institution to mislead the government. Specifically, by reporting that there is evidence of an imminent threat of crisis when its signal indicates otherwise, the institution could prompt the government to delegate the policy to the expert. Understanding that the institution categorically prefers delegation, the government expects the IO to send the message $m_{I}=1$ regardless of the signal it receives, and consequently disregards the institution's message. As a result, there is no truth-telling equilibrium when $k_{1}<k<k_{2}$. We summarize these results in the following proposition.

Proposition 1: If the domestic expert is unbiased, then no truth-telling equilibrium exists in which the government delegates the policymaking decision to the expert contingent on the institution's message.

Proposition 1 states that there is no truth-telling equilibrium in which the IO truthfully reports its signal and the government conditions its decision about whether to delegate on the IO's message. In other words, when domestic experts are known 
to share the preferences of the IO precisely, and these preferences differ from those of the government, there are no circumstances under which the institution can influence the government's decision about whether to delegate. The government ignores the institution's message altogether, regardless of the cost of implementing the policy and regardless of how well informed the IO may be.

\section{Reform-Biased Expert}

We now turn to the possibility that domestic experts may be biased. Suppose the expert is biased toward policy $x=1$ with probability $\pi$, and unbiased otherwise. A biased expert, in this sense, may be thought of as an agent who makes principled decisions rather than pragmatic decisions that depend on the prevailing circumstances. Both types of experts will choose according to their true preferences if the decision is delegated to them. This means that the biased expert will choose $x_{E}=1$, while the unbiased type will choose a policy that is consistent with the expert's updated belief about the state of the world.

Interesting new findings emerge in this scenario. First, the IO no longer categorically prefers policy delegation: if $\pi$ is sufficiently large, that is, the probability is high that the domestic expert is biased, the IO may prefer that the government choose its own policy rather than delegating. Second, the expected utility for the government from delegation decreases in $\pi$, so the government is more reluctant to delegate. The cost threshold below which the government will always delegate regardless of the IO's message, $k_{1}^{\prime}$, and the cost threshold above which it will never delegate, $k_{2}^{\prime}$, are smaller than $k_{1}$ and $k_{2}$ in the baseline case, respectively, that is, $k_{1}^{\prime}<k_{1}$ and $k_{2}^{\prime}<k_{2}$.

As in the baseline case, we have three cases to consider to determine whether the IO has an incentive to reveal its information to the government truthfully. The IO's message cannot change the government's behavior when $k \leq k_{1}^{\prime}$ or $k \geq k_{2}^{\prime}$, because the government either always delegates or never delegates for these values of $k$. If the cost falls between the two thresholds, that is, $k_{1}^{\prime}<k<k_{2}^{\prime}$, and the institution sends a truthful signal, the government will not delegate if the institution reports $m_{I}=0$, but will delegate if the institution reports $m_{I}=1$, because the expected benefit from letting the expert choose the policy outweighs the expected cost of implementing the policy when $s_{I}=1$. As in the baseline, this scenario makes it possible for the institution to manipulate its message, so we turn next to whether the institution has an incentive to do so in this case.

Indeed, we find that if $\pi$ is sufficiently small, that is, the domestic expert is unlikely to be biased, a truth-telling equilibrium does not exist for $k_{1}^{\prime}<k<k_{2}^{\prime}$, as in the baseline model. However, if $\pi$ is sufficiently large, that is, the probability of encountering a biased domestic expert is high, then it is not in the IO's interest to prompt the government to delegate if it believes that the state of the world is not a crisis. Delegating to a reform-biased expert is costly when the IO has observed $s_{I}=0$, because a biased expert will choose a policy $x=1$ regardless of the state of the world. Consequently, the international institution truthfully reports that it has 
observed $s_{I}=0$ when this is the case. As a result, the message $m_{I}=1$ is informative when it is sent, because the IO sends this message only when it observes $s_{I}$ $=1$. This makes it possible for the government to utilize the IO's message to decide whether or not to delegate. Ironically, the possibility that domestic experts are biased is a necessary condition for an international institution to exert influence. Governments and international institutions make common cause when neither fully trusts the domestic experts. We therefore have the following result.

Proposition 2: If with a high probability the domestic expert is reform-biased, then for some parameter range there exists a unique truth-telling equilibrium in which the government delegates the policymaking decision to the expert contingent on the institution's message.

These two propositions combine to produce a counterintuitive result: it is more difficult for international institutions to persuade governments to consult domestic experts that are known to be unbiased than to delegate policy to suspected extremists. The logic behind this finding is that the possibility that the expert is biased disciplines the IO. If domestic experts are known to be pure technocrats who fully share the institution's preferences and prescribe policies strictly based on their expertise, the international institution has an incentive to misrepresent its private information when it observes that the state of the world is not likely to be a crisis. As a result, the institution cannot credibly send a message that would persuade the government to delegate policy when it observes the opposite. On the other hand, the possibility that the expert is an activist who would prescribe extreme policies deters the institution from manipulating its message, making the institution a credible source of information for the government.

\section{Status-Quo Biased Expert}

A natural question is whether the result from proposition 2 holds for the other variant of the model, where the domestic expert may be biased toward the status quo, $x=0 .{ }^{18}$ In this case, we find that the result does not hold for any $\pi$. When the expert is biased toward policy 0 , the international institution again has an incentive to misrepresent its information for $k_{1}^{\prime}<k<k_{2}^{\prime}$; consequently, there is no truth-telling equilibrium. The intuition is as follows: when the international institution receives signal 0 , it recognizes that truth-telling will lead the government to do nothing (choosing policy 0). On the other hand, if the institution misrepresents its signal and the government delegates, there is some chance that an unbiased expert will be drawn. There is no downside to delegation from the IO's point of view: the biased expert chooses the same policy as the government $(x=0)$, while

18. As discussed earlier, a more appropriate interpretation of the "expert" in this case is a bureaucrat who has a status quo bias. 
the unbiased expert chooses $x=1$ only if the expert's signal indicates that this is optimal. Since the expert's signal is more accurate than the institution's signal, this is optimal regardless of the signal the institution receives. As a result, the institution always has an incentive to manipulate its message so that the government will delegate. The following proposition summarizes the result.

Proposition 3: If with some probability the domestic expert is status-quo biased, then no truth-telling equilibrium exists in which the government delegates the policymaking decision to the expert contingent on the institution's message.

The implication of the result is identical to that of proposition 1; that is, if the domestic expert has a status quo bias, there is no truth-telling equilibrium in which the IO truthfully reports its signal and the government conditions its decision about whether to delegate on the IO's message.

To summarize our results: first, when the cost of implementing a policy change is small, the government always delegates decision making to the expert. Second, if the cost of policy change is excessive, the government categorically refuses to delegate. So in both cases, the IO's information does not influence the government's policy. Finally, when the cost is in the intermediate range, the government has an incentive to delegate if it believes that a crisis is imminent when the IO says so; however, it does not trust the IO's message unconditionally. We show that the IO is able to credibly convey information and empower domestic experts only when those experts are believed to be biased in favor of reform with a high probability.

\section{Discussion}

The fundamental result of our analysis is that IOs can influence government policies and promote delegation to policy experts whose preferences diverge from the government's, but only when there is a sufficiently high probability that the policy experts in question are biased in favor of policy innovation. Bias, in this sense, means that the policy experts categorically prefer policy innovation irrespective of the state of the world, which is what justifies policy change from the points of view of the government and the IO. Health professionals prefer to take precautions to contain potential epidemics, even if it is possible that the public health benefits may be meager; while Chinese officials in the SARS case were prepared to accept the necessity of publicizing the crisis only if the outbreak proved to be severe. Neoliberal economists prefer market-oriented reform irrespective of the business cycle, but governments might feel that such reforms are justified only to fend off an impending financial crisis. Environmental scientists prefer to reduce the degree of global climate change regardless of whether new data indicate that projected global temperatures will be higher or lower than previously believed, but these projections may be critical to the cost-benefit calculations of politicians. The IO and the domestic expert share a bias in the sense that neither pays the 
costs of the new policy, so both are suspect from the government's point of view. However, the IO shares the government's interest in matching the policy to the state of the world; the domestic agent does not if the expert is reform-biased, and instead categorically prefers policy change.

When domestic experts are known to share the IO's preferences precisely, its message is uninformative because the institution has an incentive in every state of the world to send a message that will lead the government to delegate. Consequently, the government cannot learn anything from the IO that would allow it to update its beliefs, so the IO's message is disregarded. The same is true when domestic experts may be biased in favor of the status quo: again, the IO categorically prefers delegation, so its message is uninformative. (In this case, the biased type of domestic expert chooses the same policy as the government, so delegation costs the IO nothing, while the unbiased type of the domestic agent chooses policy innovation only when its superior information about the state of the world indicates that it is justified.) Ironically, in the cases of unbiased or status-quo-biased experts, where the government would be more willing to delegate ex ante, the IO cannot provide credible information, so domestic experts are ignored.

When domestic experts may be biased policy activists, on the other hand, governments are able to trust IOs because neither fully trusts the domestic experts. The possibility that domestic experts may be more radical than the IO disciplines the IO, deterring it from announcing that the state of the world favors radical reform unless it truly believes that this is the case. Intuitively, our results suggest that IOs are most credible when they are moderate, relative to the policy alternatives represented in domestic politics.

Readers may object to the model we analyze on the grounds that it is unrealistic to expect a government-particularly an authoritarian government- to delegate policymaking to a domestic expert. Consequently, we have analyzed a consultation variant of the game in which the expert's decision is treated as a recommendation to the government, and the government retains the choice of the final policy to implement. We find that in the context of our model, whenever a government would consult an expert, it would subsequently prefer to follow the expert's advice; consequently, all of our main results from the delegation game hold in the extended game. Our results are robust in this sense to a change in the extensive form of the game. Delegation and consultation are not equivalent generally, so we have further investigated the robustness of these findings to changes in the form of the government's utility function. We find that the equivalence result holds whenever the unit cost of implementing the policy, $k$, is small enough, even if the government's utility function is nonlinear. We retain the delegation framework because we believe that when consultation and delegation are distinct, delegation is substantively more significant. For example, policymaking in some contexts requires delegation as a practical matter, as is illustrated by the examples that we discuss in the following sections. Furthermore, a substantial theoretical literature argues that effective consultation generally requires delegation. Without delegation, experts may not have an incentive to collect informa- 
tion or specialize ${ }^{19}$ Moreover, Dessein finds that when the preference difference between the principal and the agent is large, the agent has an incentive not to fully reveal private information as analyzed by Crawford and Sobel, and delegation, which grants authority over the use of critical resources, is preferable to communication..$^{20}$ Finally, Gailmard shows that without credible commitment any mechanism that elicits private information reduces to cheap talk, and delegation is preferable to such mechanisms. ${ }^{21}$

\section{An Illustration: The SARS Outbreak in China}

The outbreak of SARS in China serves as an illustration of the mechanism of our model. The new administration of President Hu Jintao and Premier Wen Jiabao came into office in March 2003 in the midst of a rapidly spreading epidemic, and initially the central government was deeply uncertain about the severity of the crisis. Lower-level officials had much better information than the central government, because censorship, hierarchical reporting structures, and career incentives filtered out bad news before it could reach the top. There was a conflict of interest between policy experts and government officials: health experts favored publicity, while party functionaries insisted on downplaying the severity of the crisis to contain social unrest. Indeed, provincial officials in Guangdong sought to hide the outbreak in January and forbade newspaper reports in February, and, as late as March, the Ministry of Health prohibited Beijing hospitals from disclosing infections. The WHO played a pivotal role by drawing international attention to the epidemic on 15 March, which convinced the leaders of the central government to intervene. The new leaders carried out a purge of top officials, including the minister of health and the mayor of Beijing, and the new leadership publicized the outbreak and took strong steps to contain its spread.22

From the point of view of our model, the key features of the SARS incident are that the top Chinese leaders were uninformed about the severity of the crisis; an international organization, the WHO, was better informed and sounded the alarm; local experts had the highest-quality information; the Chinese leadership was initially skeptical about the WHO's motives; and the WHO's signals led to personnel changes that spelled a lasting shift in policy. The incident highlighted the positions of both types of biased agents in our model: government officials displayed a status quo bias, and health experts who advocated reform were suspected of disloyalty.

The initial response to the SARS outbreak was secrecy and inaction. SARS emerged in Guangdong Province in southern China in November 2002 and was

19. See Gilligan and Krehbiel 1987; and Aghion and Tirole 1997.

20. See Dessein 2002; and Crawford and Sobel 1982.

21. Gailmard 2009.

22. "Outbreak Gave China's Hu an Opening; President Responded to Pressure Inside and Outside Country on SARS," Washington Post, 13 May 2003, A1. 
known to provincial officials no later than 1 January 2003, when an investigative team was dispatched to Heyuan. Officials hid the evidence, however, and waited at least a month before notifying local hospitals. The outbreak was reported to the Ministry of Health on 7 February, and it dispatched its own fact-finding team two days later. By this time, 900 people had been infected in Guangzhou, almost half of whom were health professionals. The next day, a swarm of cellular phone text messages spread the news of the outbreak throughout China. Nevertheless, the provincial party secretary, Zhang Dejiang, continued to forbid newspapers to report on the epidemic. A struggle ensued between Zhang (no relation of the minister of health of the same last name) and the provincial governor, Huang Huahua, who authorized an article on the outbreak in Guangzhou Daily. The president-designate $\mathrm{Hu}$ intervened and declared freedom of the press to report on the epidemic, and for one week there was a flood of information in local papers. Zhang reimposed censorship on 23 February, citing risks to political stability. Ministry of Health officials continued to prohibit Beijing hospitals from disclosing SARS cases to the media in March. Reasons subsequently cited for secrecy included fears of damaging consumer confidence, deterring foreign investment, and undermining political stability.

In terms of our model, this first stage of the SARS crisis was one in which the status-quo-biased domestic bureaucratic apparatus was in charge on the ground. As our model predicts, the WHO found it challenging to convince the Chinese government of the existence and severity of the crisis. Indeed, the top leaders were largely invisible at this stage, leaving the WHO officials to struggle with the resistance put up by the Ministry of Health. The WHO received early signals about the SARS outbreak through its Global Outbreak Alert and Response Network, and made its first request for information from the Chinese Ministry of Health on 10 February. The ministry responded on 11 February that there had been 300 cases of "atypical influenza" in Guangdong Province, including five fatalities, but the situation was under control. ${ }^{23}$ The Ministry of Health blocked two WHO teams sent to investigate the outbreak from leaving Beijing. On 12 March, the WHO intervened by issuing its first global health alerts about the virus, which it labeled a "worldwide health threat," and on 15 March it labeled the condition produced by the unknown pathogen "SARS." This publicity caused a sharp drop in tourism and business travel to China, and led Morgan Stanley to lower its estimate of economic growth in Asia, aside from Japan, from 5.1 percent to 4.5 percent. ${ }^{24}$ Finally, China allowed a group of WHO experts to travel to Guangdong Province to assess the situation on 23 March. The Chinese government admitted that SARS had spread beyond Guangdong Province but claimed there were only a few cases. The WHO recommended additional measures to control the spread of the disease on $27 \mathrm{March}$,

23. Fidler 2004, 74.

24. "SARS: From China's Secret to a Worldwide Alarm," International Herald Tribune, 7 April 2003. 
however, and on 2 April it issued its first-ever travel advisory, warning that Guangdong Province and Hong Kong were unsafe because of the SARS epidemic. The minister of health denied the scale of the outbreak the following day, but a Chinese doctor sent an open letter to the Western press - at great personal risk-that challenged the official data about the number of infections. ${ }^{25}$ Moving beyond the careful neutrality they had cultivated up to this point, WHO officials seized upon the evidence produced by medical professionals to contradict Minister Zhang's figures and criticize their lack of candor. This ushered in the second stage of the SARS crisis.

The dilemma for the Chinese government was whether trust or mistrust was riskier. Trusting the WHO analysis of the gravity of the SARS threat implied acknowledging an embarrassing error, opening up a national discussion of the outbreak, accepting negative publicity, and courting political unrest. A similar discussion in the wake of the Chernobyl disaster in 1986 was widely credited with hastening the political transformation that ultimately led to the collapse of the Soviet Union. The Chinese leadership was determined to avoid Mikhail Gorbachev's error and the uncertain circumstances of a leadership transition made them more cautious, rather than less so. The WHO did not internalize any of these risks. On the other hand, the WHO had incentives to avoid crying "wolf" in a situation that would be embarrassing to the Chinese government. The WHO's effectiveness depends on its reputation as an honest, nonpartisan advisor on public health matters, and it would be costly to that reputation to make destabilizing claims that turned out to be false. If it could rely on the discretion of a disinterested domestic expert, this might not be overly risky; but Chinese experts appeared likely to push for a response that the regime considered radical and destabilizing. Consequently, the WHO was unlikely to send a warning unless it had reason to believe that SARS was a grave threat. In terms of our model, the WHO warning was credible because responding to it would empower domestic health professionals who appeared likely to support radical reforms. This would be costly to the WHO's standing in China, should it subsequently be determined that SARS had not posed a grave threat, so the existence of the radicals lent the WHO credibility as a moderate voice.

The Chinese government abruptly changed course on 17 April. Rather than rejecting the WHO's assertions, the Chinese government moved to replace its top health officials and begin to cooperate with the WHO. President $\mathrm{Hu}$ told the Politburo that the government had hidden the extent of SARS infection and launched an all-out effort to contain the disease. Within days, a number of high officials had been replaced, including the obstructionist health minister, Zhang Wenkang, and Beijing's mayor, Meng Xuenong. Their replacements quickly announced the government's intentions to increase transparency and, in particular, to work closely with the WHO. The position of health minister was filled by Vice Premier Wu Yi, who had played a key role in negotiating China's accession 
to the WTO. Liu Qi, a Politburo member with responsibility for the capital, emphasized the need to "strengthen international cooperation, especially with the WHO," and invited the WHO to nominate experts to serve on Beijing's SARS control working group. Wang Qishan, the acting major of Beijing, emphasized the need for "transparency." 26 Executive Vice-Minister of Health Gao Qiang announced revised figures of the number of people infected by SARS, new measures to combat its spread, and subsidies for affected individuals and for hospitals providing treatment. $^{27}$

The Chinese government eventually mobilized substantial resources to contain the spread of SARS, and shortened the week-long May Day vacation to one day to prevent holiday travel from spreading the disease. WHO officials emphasized that publicity was an essential element of their strategy to control the spread of infection. ${ }^{28}$ These efforts were successful by June, when the number of new SARS cases slowed to a trickle. A sweeping set of policy reforms was introduced by the new minister of health, including increasing investment in health care and sanitation, particularly in rural areas, and creating a national disease control network. ${ }^{29}$ Military hospitals, which had refused to report SARS cases outside of the military chain of command, were for the first time subordinated to the Ministry of Health. Chinese authorities moved to expand cooperation with the WHO broadly in the field of public health, and official reports took pains to emphasize the degree of cooperation taking place at local and national levels. ${ }^{30}$

\section{Additional Implications: The Limits of IO Influence}

Our analysis has observable implications for the way in which IOs exert influence, for the conditions under which they can be trusted, and for the types of policies that they can fruitfully promote. The first implication is that IOs exert influence by activating the latent influence of reform-minded policy communities within the countries they are attempting to sway. This result resonates with recent empirical work, but the causal mechanism we identify stands in stark contrast to the conventional wisdom in the literature. The literature on policy diffusion suggests that IOs play a catalytic role in spreading policy ideas, but that these ideas

26. "Chinese Official Meets WHO Representative, Beijing to Give Full Cooperation," Xinhua News Agency (via BBC Monitoring), 27 April 2003.

27. "SARS Cases Up in Beijing," China Daily, 21 April 2003.

28. For example, one of the most effective changes in procedure introduced in Guangdong was to train medical receptionists to segregate patients with coughs and fevers from other patients until they could be diagnosed. "WHO Team Praises Guangdong," The Straits Times, 10 April 2003.

29. "WHO Official in China Praises Authorities For 'Excellent' Anti-SARS Work," Xinhua News Agency (via BBC Monitoring), 11 June 2003.

30. Qian Tong and Cheng Ying, "Being Close To and Responsible For the People: New Chinese Government's Efforts To Combat 'Atypical Pneumonia' Are Fully Affirmed," Xinhua News Agency (via BBC Monitoring), 29 April 2003. 
take root when conditions are ripe within domestic politics. Recent research on the IMF has emphasized the importance of domestic policymaking elites who form transnational alliances with international bureaucrats and share similar training. For example, Chwieroth argues that the presence of "sympathetic interlocutors," or officials in developing countries who share similar perspectives with IMF officials because they share a common educational background, is associated with IMF lending and with liberalization of the capital account. ${ }^{31}$ Our model proposes a very different interpretation of these findings. The IMF is influential not when local elites exactly share its objectives, but when local elites are likely to favor more radical reforms, so that the IMF is able to pose as a moderate advisor.

IOs promote policy change by empowering local experts. Policy experts play a crucial role because national governments are suspicious of the advice of international agencies, because they know that their preferences diverge. Domestic experts are not held in less suspicion - if they were, the mechanism would break down - but precisely because they are independent agents who might run out of control, it is possible for an IO to send a credible signal when a crisis is severe enough to justify the risk. Interactions with the IMF tend to raise the profile of the finance ministry and the central bank within a country's policymaking process, and often promote unknown, technocratic economists into positions of political prominence. An example is Leszek Balcerowicz who was a virtually anonymous young economist in 1989, but took the central role in developing Poland's strategy of economic transition after Tadeusz Mazowiecki tapped him to negotiate with the IMF, and later in the decade emerged as the leader of a center-right party in his own right. Balcerowicz turned out to be a committed reformer who would have favored rapid privatization and a drastic break with the past regardless of the economic circumstances, and he staked out a strategy for shock therapy that went far beyond the IMF's proposals. ${ }^{32}$

A second implication of our analysis is that the influence of IOs should decline as domestic policy experts moderate their positions. The surprising implication of the model is that IOs are most influential when domestic policy experts are not trusted; when the experts become credible and move into the mainstream, in contrast, the scope for IOs to influence policy is curtailed. Continuing to use the example of the IMF, our model suggests that neoliberal policymakers are able to play a critical role in IMF influence only because they represent policy extremists, whose far-right positions allow the IMF to signal credibly the urgency of policy reform. The IMF attempts to moderate inflation and increase macroeconomic stability, but it does not categorically prefer strategies of voucher privatization, fixed exchange rates, or shock therapy. When it signals that the economic situation is critical, however, this tips domestic politics in favor of the experts, who may turn out to be radical reformers. This, in fact, is what makes the IMF's signals credible, because

31. See Chwieroth 2007 and 2013.

32. See Balcerowicz 1992; and Stone 2002. 
it would not prefer extreme economic policies if the economic situation were less critical.

The IMF enjoyed remarkable influence in the early 1990s in Argentina and Brazil, both countries that had experimented with populist governments and hyperinflation after their transitions to democracy. In both cases, the IMF succeeded in impressing upon new governments that overcoming hyperinflation required drastic macroeconomic policy corrections, and both countries turned to technocrats to head their economic policy teams. After Argentina suffered successive waves of hyperinflation, the Peronist President Carlos Menem reluctantly turned the economy portfolio over to Domingo Cavallo, a former central banker, whom he knew to hold considerably more orthodox economic views than his own. In Brazil, the social democratic Minister of Finance (and later President) Fernando Cardoso turned to a group of young, American-educated economists to devise a radical plan to contain inflation. Both countries opted for rather extreme forms of exchange-ratebased stabilization: Brazil adopted the Real Plan, which pegged its new currency to the dollar, and Argentina adopted its Convertibility Law, which established a currency board regime and fixed the peso at parity with the dollar. The IMF was initially skeptical of both proposals. Although the IMF subsequently became deeply involved in supporting fixed exchange rate regimes, its view at this time was that a fixed exchange rate can be a useful nominal anchor to slow inflation during a transition, but is not a sustainable policy and requires an explicit exit strategy. Again, in terms of our model, the radical proposals of domestic experts rendered the IMF a moderate voice. However, the IMF's insistence on the severity of the crisis and the need for radical policy change lent crucial credibility to the domestic policy teams' calls for economic austerity.

By the late 1990s and the first years of the next decade, however, the IMF's leverage had deteriorated markedly in Brazil and Argentina as domestic experts moved into the political mainstream. This is surprising, because Brazil and Argentina had both embraced the Washington consensus; each had expanded its analytical capacity, and each had heavily recruited American-trained economists to staff its ministries. The IMF no longer had to search high and low to find interlocutors who spoke its language. Indeed, Brazil and Argentina had become exporters of economic expertise, and officials from those countries had come to exercise important responsibilities in the IMF. Ironically, however, the IMF staff found it harder to convince the ministries to change their views now that the economists were on the inside. ${ }^{33}$ This is all the more surprising because the policy of following IMF advice seemed to have worked, and no longer seemed extreme. Circumstances had shifted, however, so that the policy to which local experts were committed-exchange-rate-based stabilization-was no longer a radical reform proposal. Fixed exchange rates had become the status quo, and their proponents had become conventional politicians. Elections had been waged and won on the basis 
of the fixed exchange rate, and opposition parties had come into office pledging to defend the peso and the real.

The macroeconomic framework based on a fixed parity became unsustainable, however, as chronic budget deficits fueled inflation and international competitiveness deteriorated. IMF officials repeatedly called on the governments of Brazil and Argentina to reduce their budget deficits and their rapidly accumulating foreign debts, as mounting budget deficits threatened to unleash a spiral of exploding debt dynamics and pose the specter of default. ${ }^{34}$ IMF officials attempted to convince the Brazilian government to devalue its currency in 1998 to avoid a crisis, but Gustavo Franco, the chairman of the central bank, was a Harvard-trained economist who insisted that the announced crawling peg be defended. Brazil suffered a sharp currency crisis in 1999. When Argentina entered a protracted crisis in 2001, President Fernando de la Rua refused to take decisive action because his finance minister, Domingo Cavallo, the architect of the Convertibility Law, was confident that he could avoid default without devaluing the peso. A crucial year was lost, and when the currency crisis struck, it led to bank runs, default on the national debt, and economic collapse; the president resigned and fled the capital in a helicopter. In Argentina and Brazil, the IMF could persuade governments to take radical medicine when it could pose as a moderate advisor, but it lost its credibility when it was more alarmist than the domestic advisors.

A third and broader implication of the model is that IOs maximize their influence if they produce relatively moderate proposals compared with domestic groups that vie for influence. Again, the IMF provides a good illustration because its influence has been at its height when it has taken relatively moderate policy stances. For most of its history, the IMF has lagged behind rather than led the call for market liberalization. The IMF was originally intended to safeguard the system of fixed exchange rates foreseen at Bretton Woods, and this mandate was assumed to require the maintenance of capital controls. ${ }^{35}$ This stance shifted only gradually, and it was not until abolishing capital controls had become the agenda of the European Union and the Organization for Economic Cooperation and Development (OECD) that IMF Managing Director Michel Camdessus sought to make it a part of the IMF's official mandate. ${ }^{36}$ This initiative was largely discredited by the Asian financial crisis of 1997, and the effort to change the formal rules was abandoned in the following year, although pushing for capital liberalization became the unofficial policy of the IMF in the 1990s.

Meanwhile, the IMF carried out a "silent revolution" that dramatically increased the comprehensiveness and intrusiveness of the conditionality attached to its loans. ${ }^{37}$ A minority of IMF loans was covered by binding policy conditionality in the 1970 s,

34. See Mussa 2002; and Stone 2011.

35. See Helleiner 1994; and Pauly 1997.

36. Abdelal 2007.

37. See Boughton 2001; Gould 2006; Dreher and Jensen 2007; and Dreher and Vaubel 2004. 
but conditionality became the norm in the 1980s and universal in the 1990s. The scope of policy reforms required under IMF programs expanded rapidly, from an initial concentration on core macroeconomic policy indicators to a widening circle of economic policies. The striking influence of the IMF in the early 1990s coincided with revolutionary developments in Eastern Europe that discredited state management of the economy and created political space for experimentation with market-oriented reforms. In the process, the IMF moved beyond its traditional competency in macroeconomic policy and began to grapple with the structural features of national economies presumed to retard growth. In the wake of the Asian crisis, the IMF initially stepped up its conditionality and pioneered a new round of conditions targeted at the financial sector.

The combination of capital liberalization and expanded conditionality led to a profound crisis of legitimacy for the IMF. The IMF was widely blamed for pursuing an excessively severe economic contraction in Korea and excessively ambitious microeconomic reforms in Indonesia, and unsuccessful experiments with IMF programs polarized politics in many post-Communist and Latin American countries. Even IMF insiders and sympathetic outsiders began to speak of a problem with legitimacy, and this was generally linked to calls to "streamline" conditionality and increase the degree of "ownership" of programs by member governments. ${ }^{38}$ The most visible symptom of the crisis was that by early 2008 the IMF was left virtually without borrowers, and because the IMF's income comes from the interest on its loans, it was forced to announce a 10 percent staff reduction. Those constraints were relaxed by the advent of the global financial crisis in fall 2008, which brought the IMF many new customers, but the calls for reforming the IMF and increasing the share of votes on its executive board held by developing countries have grown. In an effort to address the crisis, quota and vote shares in the IMF were revised in 2008, and new revisions were announced in 2010 that shifted approximately 6 percent of voting power from the governments of advanced economies to emerging market countries. The implication of our model is that IMF influence was maximized in the early 1990s, when it was relatively moderate compared to the radical reformers taking office in Eastern Europe and Latin America. Its subsequent decline in influence coincided with its own drift to the right, which made governments skeptical when the IMF tried to pose as an honest broker between themselves and their own domestic experts.

\section{Conclusion}

Is it possible for IOs to persuade governments to delegate policymaking authority to experts? If so, this provides a mechanism by which IOs can exert a socializing 
influence: experts will gradually change government policies to bring them into line with international norms. Policy change imposes costs on government elites, however, so the question is why a government would allow itself to be convinced to devolve power to experts. This behavior becomes particularly puzzling when the interests of government elites diverge from the interests of IOs, so that the arguments that IOs use are immediately suspect. We analyze the possibility that an IO and a government cooperate in this situation while allowing the strategic incentives to be fully played out.

Our model is a game of incomplete information in which an international institution and a domestic policy expert receive private signals about the state of the world, the institution sends a public signal, and a government must decide whether to implement a policy reform or delegate policy to an expert who has superior information but may not share its preferences. We conclude that persuasion is possible, but only when there is an expected preference difference between the IO and domestic experts, and only when the international institution holds the more moderate policy position. In such cases, the IO can send a credible signal that directs the government's attention to domestic experts and makes their expertise policy relevant. The intuition for our results is straightforward: if the policy the expert chooses is exactly what the IO would like it to choose, the IO has an incentive to misrepresent its private information in order to convince the government to delegate authority. The IO can credibly communicate its private information only if it shares the government's concern that the domestic experts may be biased. This stands in contrast to the conventional wisdom, which holds that IOs are most influential when some domestic constituencies share their preferences.

In our model, it is possible for IOs to be more moderate than domestic experts because IOs seek to match policy to the objective state of the world, while some types of experts have ideological preferences that do not depend on the state of the world. For example, Chinese medical professionals may categorically prefer openness about the public health challenges facing the country regardless of the virulence of a particular virus, and reformist economists may categorically prefer privatization and reduced public spending, regardless of the probability of a financial crisis. The WHO might also categorically prefer openness on the part of the Chinese government, and the IMF might also prefer to see countries categorically implement market-oriented reforms, but IOs also have disincentives to mislead the governments that they seek to influence. The true state of the world will be revealed at some point, and the IO's reputation as an honest advisor would suffer if it had warned about an impending crisis that never materialized, particularly if its warning had impelled a skeptical government to undertake costly policy corrections. IOs may nevertheless have compelling incentives to stretch the truth when there is uncertainty regarding the true state of the world, but the possibility that the domestic experts are ideologically motivated types that will implement unnecessary policy changes can deter them from issuing warnings that are not supported by evidence.

Our analysis has implications for the mechanism by which IOs exert influence, for the domestic conditions that limit that influence, and for the types of influence 
that can be exerted effectively. When IOs influence domestic politics in our model, they do so by promoting the careers of elite experts, possibly with activist agendas. Such an effect need not come about because IOs intentionally promote the careers of reform-biased experts, and this is not what happens in our model; rather, IOs take calculated risks when they observe crisis signals that have the potential to involve biased experts in policymaking. Consequently, environmental IOs can promote the careers of environmental scientists who prefer activist policies to reverse pollution and retard global climate change, and economic IOs can promote the careers of economists who prefer reformist policies. Such a phenomenon may shift policy baselines and bring about convergence in government policies over time.

This mechanism imposes domestic scope conditions on IO influence. The role of biased experts in facilitating communication has a surprising implication: far from being an obstacle to international cooperation, polarized domestic politics may be a necessary condition for IOs to exert effective influence. Some of the most striking cases of IO influence that we have identified occurred when expert opinion was sharply divided, allowing IOs to send credible signals because there was a real possibility of delegation to an ideologically motivated type. On the other hand, when domestic experts move into the political mainstream, IOs may no longer be able to credibly signal the need for reform.

Finally, the results have implications for the content of policy advice that can be credibly communicated. IOs facilitate cooperation by persuading member governments to take actions that are in their own interests, and this is only possible if IOs can establish trust. Trust is inherently problematic, however, because IOs aggregate their members' interests, which are unlikely to be aligned with those of a particular member during a crisis. Our results indicate that persuasion and trust are possible only when the IO takes a position that is moderate with respect to the policy alternatives provided by domestic politics. IOs can exert effective persuasion only within a relatively narrow range, and effectiveness demands attention to domestic politics.

\section{Appendix: Proofs of Propositions}

\section{Proposition 1}

Proof. Suppose $I$ truthfully reports its signal, that is, $m_{I}=s_{I} \in\{0,1\}$. We show that for some parameter range of $k$, this cannot be an equilibrium.

(1) Suppose $m_{I}=0$ and it is public knowledge. Then the players' updated belief that $\theta=1$ is $\mu_{0}=\operatorname{Pr}\left(\theta=1 \mid m_{I}=0\right)=1-\alpha \cdot{ }^{39}$ If $G$ chooses policy itself, then the policy is the solution to the following maximization problem: 


$$
\max _{x \geq 0} E U_{G}\left(x \mid m_{I}=0\right)=\left(1-\mu_{0}\right)(-x)+\mu_{0}(x-1)-k x
$$

The optimal solution is

$$
x_{G}= \begin{cases}0 & \text { if } k \geq 2 \mu_{0}-1, \\ 1 & \text { if } k<2 \mu_{0}-1\end{cases}
$$

Because $\mu_{0}<1 / 2$ and $k>0, G$ will choose $x=0$. Now consider $G$ 's decision whether to delegate the policy choice to $E$. Given $s_{I}=0$, the expert will receive $s_{E}=0$ with $\operatorname{Pr}\left(s_{E}=0 \mid s_{I}=0\right)=\alpha \beta+(1-\alpha)(1-\beta)$ and $s_{E}=1$ with $\operatorname{Pr}\left(s_{E}=1 \mid s_{I}=0\right)=\alpha+\beta-2 \alpha \beta$. If $E$ receives $s_{E}=0$, E's updated belief about the state of the world being 1 is $\operatorname{Pr}\left(\theta=1 \mid s_{E}=0, m_{I}=0\right)$ $=\frac{(1-\alpha)(1-\beta)}{1-\alpha-\beta+2 \alpha \beta}<\frac{1}{2}$, and it will recommend $x=0$. If $E$ receives $s_{E}=1$, $E$ 's updated belief about the state of the world is $\operatorname{Pr}\left(\theta=1 \mid s_{E}=1, m_{I}=0\right)$ $=\frac{(1-\alpha) \beta}{\alpha+\beta-2 \alpha \beta}>\frac{1}{2}$, in which case $E$ will choose policy $x=1$. Essentially, because the quality of the expert's signal is better than the institution's, the expert will choose a policy that is consistent with its own signal. As a result, by delegating the policy to $E$, the expected utility for $G$ is $E U_{G}\left(E \mid m_{I}=0\right)=\beta-1$ $-(\alpha+\beta-2 \alpha \beta) k$. $G$ will compare this expected utility with that from choosing a policy by itself after I's message, $E U_{G}\left(\neg E \mid m_{I}=0\right)=\alpha-1$. $G$ will choose the action that gives it a higher expected utility of the two. We find that if $k<\frac{\beta-\alpha}{\alpha+\beta-2 \alpha \beta}$, then $G$ will delegate.

(2) Suppose $m_{I}=1$. Then $G$ knows $\theta=1$ with $\mu_{1}=\operatorname{Pr}\left(\theta=1 \mid m_{I}=1\right)=\alpha$. If $G$ chooses policy itself, then the policy is the solution to the following maximization problem:

$$
\max _{x \geq 0} E U_{G}\left(x \mid m_{I}=1\right)=\left(1-\mu_{1}\right)(-x)+\mu_{1}(x-1)-k x
$$

The optimal solution is

$$
x_{G}= \begin{cases}0 & \text { if } k \geq 2 \mu_{1}-1, \\ 1 & \text { if } k<2 \mu_{1}-1 .\end{cases}
$$

Because $\mu_{1}>1 / 2, G$ can either choose $x=0$ or $x=1$, depending on the size of $k$. For $k \geq 2 \alpha-1, G$ will choose $x=0$. 
Now consider $G$ 's decision whether to delegate the policy choice to $E$. Given $s_{I}$ $=1$, by delegating the policy to $E$ the expected utility for $G$ is $E U_{G}\left(E \mid m_{I}=1\right)$ $=-1+\beta-(1-\alpha-\beta+2 \alpha \beta) k$. $G$ will compare this expected utility with that from choosing a policy itself after I's message. Suppose $k \geq 2 \alpha-1$, then $E U_{G}\left(\neg E \mid m_{I}=1\right)=-\alpha$. We find that if $k \geq \frac{\alpha+\beta-1}{1-\alpha-\beta+2 \alpha \beta}>2 \alpha-1$, then $G$ will choose its own policy; if $2 \alpha-1 \leq k<\frac{\alpha+\beta-1}{1-\alpha-\beta+2 \alpha \beta}$, then $G$ will delegate. Suppose $k<2 \alpha-1$, then $E U_{G}\left(\neg E \mid m_{I}=1\right)=\alpha-1-k$. We find that $G$ will choose its own policy, if $k \leq \frac{\alpha-\beta}{\alpha+\beta-2 \alpha \beta}$. The condition cannot be true because $\beta>\alpha$; therefore, in this case $G$ will always delegate. In sum, if $k<\frac{\alpha+\beta-1}{1-\alpha-\beta+2 \alpha \beta}$, then $G$ delegates. Compared with the case $m_{I}=0$, for a larger range of $k, G$ will delegate. ${ }^{40}$

Given $G$ 's strategy, does $I$ have an incentive to deviate from the truth-telling strategy?

Suppose $s_{I}=0$. If $I$ reports truthfully so that $m_{I}=0$, then $G$ will choose its own policy if $k \geq \frac{\beta-\alpha}{\alpha+\beta-2 \alpha \beta}$. If $I$ deviates from truth-telling and sends $m_{I}=1$ to $G$, then $G$ will choose its own policy if $k \geq \frac{\alpha+\beta-1}{1-\alpha-\beta+2 \alpha \beta}$. Because the quality of $E$ 's information is higher than that of the institution's, $I$ is better off when $G$ delegates regardless of the signal that it received $(\beta-1>\alpha-1>-\alpha)$. Let $k_{1}$ $=\frac{\beta-\alpha}{\alpha+\beta-2 \alpha \beta}$ and $k_{2}=\frac{\alpha+\beta-1}{1-\alpha-\beta+2 \alpha \beta}$. Now we consider three scenarios of the cost:

1. $k \leq k_{1}$, then $G$ will delegate receiving either message from $I$. So $I$ has no incentive to lie.

2. $k_{1}<k<k_{2}$, then $G$ will not delegate when $m_{I}=0$, but will delegate when $m_{I}=1$. So $I$ has an incentive to lie.

3. $k \geq k_{2}$, then $G$ will not delegate in either case. So $I$ has no incentive to lie.

As a result, $I$ has an incentive to lie if $k_{1}<k<k_{2}$.

Suppose $s_{I}=1$. Again we have three cases to consider and only when $k_{1}<k$ $<k_{2}$, $G$ will delegate contingent on $I$ 's message. But in this case, $I$ has no incentive to lie because $G$ will delegate if $I$ reports truthfully, and will not delegate if $I$ reports $m_{I}=0$. As a result, $I$ will always tell the truth when $s_{I}=1$.

40. It can be shown that $\frac{\alpha+\beta-1}{1-\alpha-\beta+2 \alpha \beta}>\frac{\beta-\alpha}{\alpha+\beta-2 \alpha \beta}$. 
In sum, when $\frac{\beta-\alpha}{\alpha+\beta-2 \alpha \beta}<k<\frac{\alpha+\beta-1}{1-\alpha-\beta+2 \alpha \beta}$, there is no truthtelling equilibrium; for other values of $k$, a truth-telling equilibrium exists; however, the government ignores IO's message and either always delegates $\left(k \leq \frac{\beta-\alpha}{\alpha+\beta-2 \alpha \beta}\right)$ or never delegates $\left(k \geq \frac{\alpha+\beta-1}{1-\alpha-\beta+2 \alpha \beta}\right)$.

\section{Proposition 2}

Proof. Suppose with $\pi$ the expert is reform-biased, that is, the expert always prefers policy 1 . Below we show that if $\pi>\frac{\beta-\alpha}{\alpha+\beta-1}$, then there is a truth-telling equilibrium.

Consider the equilibrium in which $I$ truthfully reports its signal, that is, $m_{I}=s_{I}$ $\in\{0,1\}$.

(1) Suppose $m_{I}=0$ and it is public knowledge. Then the players' updated belief that $\theta=1$ is $\mu_{0}=\operatorname{Pr}\left(\theta=1 \mid m_{I}=0\right)=1-\alpha$. If $G$ chooses policy by itself, then the policy is the solution to the following maximization problem:

$$
\max _{x \geq 0} E U_{G}\left(x \mid m_{I}=0\right)=\left(1-\mu_{0}\right)(-x)+\mu_{0}(x-1)-k x
$$

The optimal solution is

$$
x_{G}= \begin{cases}0 & \text { if } k \geq 2 \mu_{0}-1, \\ 1 & \text { if } k<2 \mu_{0}-1\end{cases}
$$

Because $\mu_{0}<1 / 2$ and $k>0, G$ will choose $x=0$. Now consider $G$ 's decision whether to delegate the policy choice to the expert $E$. $G$ knows that with $1-\pi, E$ is unbiased and will choose a policy that is consistent with $E$ 's updated belief about the state of the world; with $\pi, E$ is biased and will recommend simply $x=1$ regardless of the signal $E$ receives. As a result, by delegating the policy to $E$ the expected utility for $G$ is:

$$
\begin{aligned}
E U_{G}\left(E \mid m_{I}=0\right)= & -\alpha \beta \pi(1+k)-(1-\alpha)(1-\beta)(1-\pi+\pi k) \\
& -\alpha(1-\beta)(1+k)-\beta(1-\alpha) k
\end{aligned}
$$

$G$ will compare this expected utility with that from choosing a policy itself after I's message, $E U_{G}\left(\neg E \mid m_{I}=0\right)=\alpha-1$. Because having the biased expert is even more likely to lead to policy $x=1$, the threshold value of $k$ that will give $G$ an incentive to delegate is going to be smaller than 
the case where there is no biased expert. We find the threshold to be $k_{1}^{\prime}$ $=\frac{\beta-\alpha-(\alpha+\beta-1) \pi}{\alpha \beta \pi+(1-\alpha)(1-\beta) \pi+\alpha(1-\beta)+\beta(1-\alpha)}$, and $k_{1}>k_{1}^{\prime}$. Moreover, if $\pi<\frac{\beta-\alpha}{\alpha+\beta-1}$, then $k_{1}^{\prime}>0 .{ }^{41}$ That is, if $\pi$ is small enough, then $G$ will choose a policy by itself if $k \geq k_{1}^{\prime}$. This result is similar to the case of unbiased expert. If $\pi>\frac{\beta-\alpha}{\alpha+\beta-1}$, then $k_{1}^{\prime}<0$, which means for any positive $k, G$ will choose its own policy.

(2) Suppose $m_{I}=1$. Then $G$ knows $\theta=1$ with $\mu_{1}=\operatorname{Pr}\left(\theta=1 \mid m_{I}=1\right)=\alpha$. If $G$ chooses policy by itself, then the policy is the solution to the following maximization problem:

$$
\max _{x \geq 0} E U_{G}\left(x \mid m_{I}=1\right)=\left(1-\mu_{1}\right)(-x)+\mu_{1}(x-1)-k x
$$

The optimal solution is

$$
x_{G}= \begin{cases}0 & \text { if } k \geq 2 \mu_{1}-1 \\ 1 & \text { if } k<2 \mu_{1}-1\end{cases}
$$

Because $\mu_{1}>1 / 2, G$ can either choose $x=0$ or $x=1$, depending on the size of $k$. For $k \geq 2 \alpha-1, G$ will choose $x=0$.

On the other hand, if $G$ delegates, then the expected utility for $G$ is:

$$
\begin{aligned}
E U_{G}\left(E \mid m_{I}=1\right)= & -\beta(1-\alpha) \pi(1+k)-\alpha(1-\beta)(1-\pi+\pi k) \\
& -(1-\alpha-\beta+\alpha \beta)(1+k)-\alpha \beta k
\end{aligned}
$$

$G$ will compare this expected utility with that from choosing a policy by itself after $I$ 's message.

Suppose $k \geq 2 \alpha-1$, then $G$ will choose $x=0$ if it chooses the policy by itself, and $E U_{G}\left(\neg E \mid m_{I}=1\right)=-\alpha$. Let $k_{2}^{\prime}$ $=\frac{\alpha+\beta-1+(\alpha-\beta) \pi}{(\alpha+\beta-2 \alpha \beta) \pi+(1-\alpha-\beta+2 \alpha \beta)}>0$. We find that if $k \geq k_{2}^{\prime}$, then $G$ will choose the policy by itself; and if $2 \alpha-1<k<k_{2}^{\prime}$, then it will delegate to the expert. ${ }^{42}$

41. It can be shown that $0<\frac{\beta-\alpha}{\alpha+\beta-2 \alpha \beta}<1$.

42. It can be shown that $2 \alpha-1<k_{2}^{\prime}$ for all $\pi>0$. 
Now suppose $k<2 \alpha-1$, then $G$ will choose $x=1$ if it chooses the policy by itself, and $E U_{G}\left(\neg E \mid m_{I}=1\right)=\alpha-1-k$. We find that $G$ will choose its own policy if $k \leq \frac{\alpha-\beta}{\alpha+\beta-2 \alpha \beta}$. The condition cannot be true because $\beta>\alpha$; therefore, in this case $G$ will always delegate. In sum, if $k<k_{2}^{\prime}$, then $G$ delegates. Compared with the case $m_{I}=0$, for a larger range of $k, G$ will delegate. ${ }^{43}$

Given $G$ 's strategy, does $I$ have an incentive to deviate from the truth-telling strategy? We first consider the case that $\pi \leq \frac{\beta-\alpha}{\alpha+\beta-1}$, so that $0<k_{1}^{\prime}<k_{2}^{\prime}$.

Suppose $s_{I}=0$. If $I$ reports truthfully so that $m_{I}=0$, then $G$ will take that information and choose its own policy if $k \geq k_{1}^{\prime}$. If $I$ deviates from truth-telling and sends $m_{I}=1$ to $G$, then $G$ will choose its own policy if $k \geq k_{2}^{\prime}$. With the existence of the biased type, $I$ is not always better off from policy delegation. Now we consider three scenarios:

1. $k \leq k_{1}^{\prime}$, then $G$ will delegate receiving either message from $I$. So $I$ has no incentive to lie.

2. $k_{1}^{\prime}<k<k_{2}^{\prime}$, then $G$ will not delegate when $m_{I}=0$, but will delegate when $m_{I}=1$. This is a case where $I$ may have an incentive to lie. If $I$ is truthful, then $G$ will not delegate and choose policy 0 . Then $I$ 's expected utility is $\alpha-1$. If $I$ lies, then $G$ will delegate to the expert. The expected utility for $I$ is $E U_{I}\left(m_{I}=1 \mid s_{I}=0\right)=\beta-1+\pi(1-\alpha-\beta)$. We find that if $\pi \geq \frac{\beta-\alpha}{\alpha+\beta-1}, I$ is better off being truthful and let $G$ choose the policy. This contradicts the assumption that $\pi \leq \frac{\beta-\alpha}{\alpha+\beta-1}$ for this case. Therefore, $I$ will always have an incentive to lie in this case. ${ }^{44}$

3. $k \geq k_{2}^{\prime}$, then $G$ will not delegate in either case. So $I$ has no incentive to lie.

It is easy to check that when $s_{I}=1$, the institution has no incentive to lie. In sum, if $\pi \leq \frac{\beta-\alpha}{\alpha+\beta-1}$, then there is no truth-telling equilibrium because $I$ has an incentive to lie when $m_{I}=0$.

Now consider the case that $\pi>\frac{\beta-\alpha}{\alpha+\beta-1}$. Because $k_{1}^{\prime}<0$ in this case, there are only two scenarios to consider:

43. It can be shown that $k_{2}^{\prime}>k_{1}^{\prime}$.

44. When $\pi=\frac{\beta-\alpha}{\alpha+\beta-1}, I$ is indifferent and we assume that $I$ will be truthful. 
1. $0<\mathrm{k}<k_{2}^{\prime}$, then $G$ will not delegate if $m_{I}=0$, but delegate if $m_{I}$ $=1$. Suppose $s_{I}=0$. From the previous analysis we find that if $\pi$ $>\frac{\beta-\alpha}{\alpha+\beta-1}$, then $I$ is better off reporting $m_{I}=0$ and let $G$ choose the policy. Therefore, $I$ will be truthful in this case. Suppose $s_{I}=1$. Again, from the previous analysis we know that for all $1 \geq \pi \geq 0, I$ receives a higher payoff from policy delegation, so $I$ will be truthful.

2. $k \geq k_{2}^{\prime}$, then $G$ will not delegate given either $m_{I}$ and choose $x=0$. So $I$ has no incentive to lie.

In sum, with the existence of the reform-biased expert, $I$ has an incentive to lie for some range of $k$ when receiving signal $s_{I}=0$; however, if the probability of encountering the biased type is sufficiently high $\left(\pi>\frac{\beta-\alpha}{\alpha+\beta-1}\right)$, then $I$ will be truthful for all $k$.

\section{Proposition 3}

The proof of proposition 3 is omitted because it is very similar to those of the other two propositions. Interested readers can refer to the authors' websites for detailed proofs.

\section{References}

Abdelal, Rawi. 2007. Capital Rules: The Construction of Global Finance. Cambridge, Mass.: Harvard University Press.

Aghion, Philippe, and Jean Tirole. 1997. Formal and Real Authority in Organizations. Journal of Political Economy 105 (1):1-29.

Balcerowicz, Leszek. 1992. 800 Dni: Szok Kontrolowany. Warsaw, Poland: Polska Oficyna Wydawn "BGW."

Barnett, Michael, and Martha Finnemore. 2004. Rules for the World: International Organizations in Global Politics. Ithaca, N.Y.: Cornell University Press.

Boughton, James M. 2001. Silent Revolution: The International Monetary Fund, 1979-1989. Washington, D.C.: International Monetary Fund.

Calvert, Randall L. 1985. The Value of Biased Information: A Rational Choice Model of Political Advice. Journal of Politics 47 (2):530-55.

Chapman, Terrence L. 2009. Audience Beliefs and International Organization Legitimacy. International Organization 63 (4):733-64.

Checkel, Jeffrey T. 1997. Ideas and International Political Change: Soviet/Russian Behavior and the End of the Cold War. New Haven, Conn.: Yale University Press.

Chwieroth, Jeffrey M. 2007. Neoliberal Economists and Capital Account Liberalization in Emerging Markets. International Organization 61 (2):443-63.

- 2013. "The Silent Revolution": How the Staff Exercise Informal Governance over IMF Lending. Review of International Organizations (forthcoming).

Crawford, Vincent P., and Joel Sobel. 1982. Strategic Information Transmission. Econometrica 50 (6):1431-51. 
Cukierman, Alex, and Mariano Tommasi. 1998. When Does It Take a Nixon to Go to China? American Economic Review 88 (1):180-97.

Dai, Xinyuan. 2005. Why Comply? The Domestic Constituency Mechanism. International Organization 59 (2):363-98.

— 2007. International Institutions and National Policies. Cambridge, UK: Cambridge University Press.

Dessein, Wouter. 2002. Authority and Communication in Organizations. Review of Economic Studies 69 (4):811-38.

Drazen, Allan. 2002. Conditionality and Ownership in IMF Lending: A Political Economy Approach. Discussion Paper 3562. London: Centre for Economic Policy Research.

Drazen, Allan, and Paul R. Masson. 1994. Credibility of Policies Versus Credibility of Policy-Makers. Quarterly Journal of Economics 109 (3):735-54.

Dreher, Axel, and Nathan M. Jensen. 2007. Independent Actor of Agent? An Empirical Analysis of the Impact of U.S. Interests on International Monetary Fund Conditions. Journal of Law and Economics 50 (1):105-24.

Dreher, Axel, and Roland Vaubel. 2004. The Causes and Consequences of IMF Conditionality. Emerging Markets Finance and Trade 40 (3):26-54.

Fang, Songying. 2008. The Informational Role of International Institutions and Domestic Politics. American Journal of Political Science 52 (2):304-21.

Fearon, James D. 1995. Rationalist Explanations for War. International Organization 49 (3):379-414.

Fidler, David P. 2004. SARS, Governance, and the Globalization of Disease. New York: Palgrave Macmillan.

Gailmard, Sean. 2009. Discretion Rather Than Rules: Choice of Instruments to Control Bureaucratic Policy Making. Political Analysis 17 (1):25-44.

Gilligan, Thomas W., and Keith Krehbiel. 1987. Collective Decisionmaking and Standing Committees: An Informational Rationale for Restrictive Amendment Procedures. Journal of Law, Economics, and Organization 3 (2):287-335.

Goldstein, Judith, and Robert O. Keohane, eds. 1993. Ideas and Foreign Policy: Beliefs, Institutions, and Political Change. Ithaca, N.Y.: Cornell University Press.

Gould, Erica R. 2006. Money Talks: The International Monetary Fund, Conditionality, and Supplementary Financiers. Stanford, Calif.: Stanford University Press.

Hawkins, Darren G., David A. Lake, Daniel L. Nielson, and Michael J. Tierney, eds. 2006. Delegation and Agency in International Organizations. New York: Cambridge University Press.

Helleiner, Eric. 1994. States and the Reemergence of Global Finance: From Bretton Woods to the 1990s. Ithaca, N.Y.: Cornell University Press.

Hills, Carla A., Peter G. Peterson, and Morris Goldstein. 1999. Safeguarding Prosperity in a Global Financial System: The Future International Financial Architecture. Washington, D.C.: Council on Foreign Relations and Institute for International Economics.

Independent Evaluation Office. 2003. The IMF and Recent Capital Account Crises: Indonesia, Korea, Brazil. Washington, D.C.: International Monetary Fund. Available at /http://www.imf.org/external/ np/ieo/2003/cac/pdf/all.pdf $\rangle$. Accessed 29 June 2012.

—. 2004. The IMF and Argentina, 1991-2001. Washington, D.C.: International Monetary Fund. Available at $\langle$ http://www.imf.org/external/np/ieo/2004/arg/eng/pdf/report.pdf $\rangle$. Accessed 29 June 2012.

International Monetary Fund. 2005. Review of the 2002 Conditionality Guidelines. Washington D.C.: International Monetary Fund. Available at 〈http://www.imf.org/external/np/pp/eng/2005/ 030305.pdf $\rangle$. Accessed 29 June 2012.

Johns, Leslie. 2007. A Servant of Two Masters: Communication and the Selection of International Bureaucrats. International Organization 61 (2):245-75.

Keohane, Robert O. 1984. After Hegemony: Cooperation and Discord in the World Political Economy. Princeton, N.J.: Princeton University Press.

Khan, Mohsin S., and Sunil Sharma. 2001. IMF Conditionality and Country Ownership of Programs. Working Paper 01/142. Washington, D.C.: International Monetary Fund. 
Kydd, Andrew H. 2003. Which Side Are You On? Bias, Credibility, and Mediation. American Journal of Political Science 47 (4):597-611.

- 2005. Trust and Mistrust in International Relations. Princeton, N.J.: Princeton University Press.

Milner, Helen V. 1997. Interests, Institutions, and Information: Domestic Politics and International Relations. Princeton, N.J.: Princeton University Press.

Mussa, Michael. 2002. Argentina and the Fund: From Triumph to Tragedy. Washington, D.C.: Institute for International Economics.

Pauly, Louis W. 1997. Who Elected the Bankers? Surveillance and Control in the World Economy. Ithaca, N.Y.: Cornell University Press.

Reinhardt, Eric. 2001. Adjudication Without Enforcement in GATT Disputes. Journal of Conflict Resolution 45 (2):174-95.

Sartori, Anne E. 2005. Deterrence by Diplomacy. Princeton, N.J.: Princeton University Press.

Simmons, Beth A. 2009. Mobilizing for Human Rights: International Law in Domestic Politics. New York: Cambridge University Press.

Stone, Randall W. 2002. Lending Credibility: The International Monetary Fund and the Post-Communist Transition. Princeton, N.J.: Princeton University Press.

- 2011. Controlling Institutions: International Organizations and the Global Economy. Cambridge, UK: Cambridge University Press.

Thomson, Robert, Frans N. Stokman, Christopher H. Achen, and Thomas König, eds. 2006. The European Union Decides: Testing Theories of European Decision-Making. Cambridge, UK: Cambridge University Press

Vreeland, James R. 2003. The IMF and Economic Development. New York: Cambridge University Press.

Woods, Ngaire. 2006. The Globalizers: The IMF, the World Bank, and Their Borrowers. Ithaca, N.Y.: Cornell University Press. 